\title{
Design of Road Longitudinal Profile, According To the Fluency and Traffic Quality of Route
}

\author{
Jūratè Vitkienè ${ }^{\mathrm{a}}$, Igor Nesterovitch ${ }^{\mathrm{b}}$, Virgaudas Puodžiukas ${ }^{\mathrm{c}}$ \\ ${ }^{a}$ Road Research Institute, Vilnius Gediminas Technical University, Linkmenu str. 28, VI corps, $5^{\text {th }}$ floor, 08217 Vilnius, Lithuania \\ ${ }^{b}$ State Educational Institution "Center of raising the qualification of leading employees and specialists "Beldorstroy": St. Kalvariyskaja 37, \\ 220073 Minsk, Republic of Belarus \\ ${ }^{c}$ Department of Roads, Vilnius Gediminas Technical University, Sauletekio al. 11, 10223 Vilnius, Lithuania
}

\begin{abstract}
A rocketing demand for cars and heavy duty freight vehicles as well as the related infrastructure and an increasing number of traffic accidents determine the need for road upgrading and necessitate the search for new solutions for the sake of improvement of the requirements pertaining to the design of longitudinal road profile. The immediate objective is to improve the traffic quality to make the roads safer and more comfortable to use. The needs of the society, convenience and comfort on roads, not to mention traffic and environmental safety, are the most significant for the road design and subsequent construction processes in the developed countries of Western Europe, the USA and Canada. These countries-specific road design rules focus on smooth, harmonious and comfortable design of any route and present the requirements on how to achieve the said smoothness and comfort. To the opinion of the authors of the present article, the Lithuanian and Belarus road design rules fail to include certain topical requirements to be posed for longitudinal road profile design in regard to road smoothness and traffic quality. The authors of the article tackle the problems associated with the longitudinal profile of the road in terms of the road smoothness, safety, convenience and comfort, viz., traffic quality on the roads of Lithuania and Belarus. As a result, some solutions of the road longitudinal profile design (i.e. the design line) are analyzed and proposed herein for potential improvement of traffic quality on the roads of the said countries.
\end{abstract}

Keywords: road design; road longitudinal profile; road smoothness; road harmoniou; road convenience and comfort; International Roughness Index (IRI).

\begin{tabular}{|ll}
\hline Nomenclature & \\
IRI & International Roughness Index $(\mathrm{m} / \mathrm{km}$, or $\mathrm{mm} / \mathrm{m})$ \\
NCHRP & National Cooperative Highway Research Program \\
PSD & power spectral density \\
EKA & Entwurfsklasse von Autobahnen (design class in Germany) \\
EKL & Entwurfsklasse von Landstraßen (design class in Germany) \\
\hline
\end{tabular}

\section{Introduction}

A growing extent of the society needs, an increasing demand for heavy duty freight vehicles and the related infrastructure, regional development and an exceptionally pending demand for cars followed by an increasing number of traffic accidents lead to the necessity of motorway upgrading via both, improvement of the existing roads and construction of the new ones. The improvement of vehicles brings changes to the requirements set for roads. Along with securing an uninterrupted movement of vehicles along roads at a permissible speed, it is also aimed at the roads to be safer and more comfortable, i.e. the improvement of traffic quality is aimed at. This further leads to the introduction of such requirements like comfortable and easy driving; harmonious, consistent, smooth, harmonious and driver-apprehensible surroundings and traffic conditions on the road. 
Solutions that would improve traffic safety are searched for and analyzed during the engineering process intended for both, construction of new roads and upgrade of the existing ones. Most often the solutions in question concern the route smoothness (and longitudinal road profile in particular), which plays a decisive role in the safety and quality of traffic.

Thus, for traffic quality improvement the road surface should be ideally smooth at least theoretically. However, design of the so-called "wavy" profile, i.e. with certain slope/inclination straights, interconnected with different radius crest and concave vertical curves or sometimes even "broken" profile, which should be absolutely unacceptable in road design (based on an international experience, i.e. design rules applicable in Western Europe, the USA and Canada) is pursued for traffic safety purposes, rational use of the relief of the locality and minimization of adverse impact on the environment.

The smoothness of road pavement is most often described by the International Roughness Index (IRI) (Sayers et al. 1986) [1]. The international roughness index (IRI) was established in 1986 by the World Bank and based on earlier work performed for the United States National Cooperative Highway Research Program (NCHRP). IRI is calculated from a measured longitudinal road profile [2] by accumulating the output from a quarter-car model [3] and dividing by the profile length to yield a summary roughness index with units of slope. The relevant response properties of an automobile are captured by a simple dynamic model known as the quarter-car model shown in Figure 1. At each wheel position the vehicle behaves as a sprung mass sitting on a suspension with stiffness and damping, which in turn is attached to the unsprung mass of the wheel, brake, and suspension components. The wheel contacts the road by a tire which acts like a spring. Road inputs to the car flex the tire, stroke the suspension, and cause the sprung and unsprung masses to vibrate in the vertical direction [4].
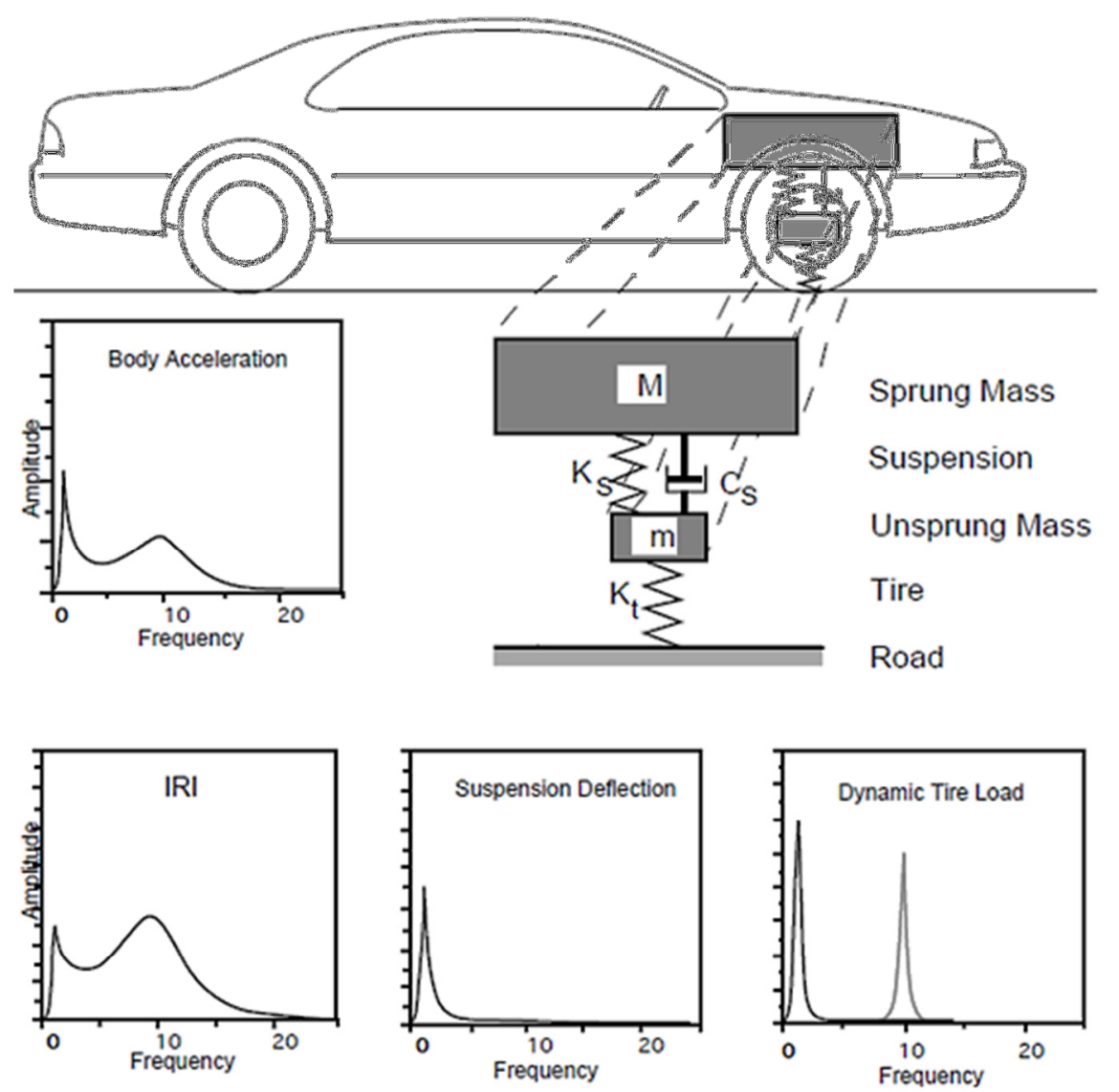

Fig. 1. The quarter-car model and Comparison of IRI with other vehicle responses

Whether the roughness is viewed as deviations in elevation (displacement inputs), slope (velocity inputs), or change of slope (acceleration inputs) the quarter car responds in a defined manner. The response can be mathematically described with a relatively simple set of dynamic equations known as a quarter-car simulation. At very low frequencies (corresponding to long wavelengths in the road) the suspension response is zero because the wheel and the vehicle body move up and down together. Road inputs at frequencies near one Hertz cause the sprung mass to resonate on the suspension producing stroke that is slightly greater than the road input. The response is maintained up through frequencies near 10 Hertz where axle resonance occurs [4]. Above the axle resonant frequency the response again drops to zero as the road bumps simply deflect the tire without producing significant suspension stroke.

The frequency response of the quarter car extends from approximately 0.5 to $20 \mathrm{~Hz}$ with some emphasis on roughness at the body bounce frequency and the axle resonance frequency. It is characteristic of motor vehicle dynamics. The rationale favouring the quarter car is the fact that it covers the appropriate frequency range responsible for exciting vehicle vibrations and emphasizes those that excite modal resonances. 
Roughness is also significant to motor vehicle performance in other ways. The existence of roughness necessitates suspension systems on motor vehicles to reduce the vibration exposure of passengers. A primary consideration in design of suspension systems is the stroke necessary to accommodate the displacements caused by roughness. Ride improves with stroke. The more generous suspension stroke in a luxury car is the primary factor that allows it to ride better than compact cars. Thus, the likely stroke in the suspension must be rationalized with available package space in a vehicle. A relevant roughness measurement should therefore encompass the qualities that determine suspension stroke requirements. The body acceleration spectrum (the power spectral density, or PSD) for suspension stoke shown in Figure 1 reveals that the body resonant mode, which is captured by the IRI, is dominant [4].

\section{Traffic quality problems resulting from the smoothness of the road longitudinal profile}

The road breaks (sudden changes) emerging due to the changed slope of the design line pose numerous inconveniences for the vehicles driving along the road. Visibility is lower in crest breaks. Moreover, a car may lose its controllability/stability due to sharp reduction of the front axle load in case of small radius curve designed there. Abrupt change in driving direction in the sag breaks of the design line, the car springs are overloaded and an unpleasant feeling is imposed on the passengers, and some other inconveniences are felt. To avoid this, design of sufficiently large radius vertical curves is recommended in design line breaks.

Frequent breaks of the design line should be avoided in the engineering of longitudinal road profile to ensure the smoothness of route. Frequent breaks in a longitudinal profile create forced vibrations/fluctuations emerging as a result of periodic forces impacting a vehicle and insufficient length of lines/straights between the break points prevents the said vibrations/fluctuations fade away/to be suppressed. The question to be answered addresses the smallest distance, i.e. design step to be applied between the design line breaks when different category roads are designed in order to ensure smoothness of their routes and conformity with traffic control requirements.

\section{Analysis and evaluation of the road longitudinal profile smoothness}

Irrespective of the selected design method (longitudinal profile breaks with vertical curves or without them), it is almost always assumed that from theoretical standpoint the longitudinal profile of the newly designed road will be ideally smooth, though it is not always so in practice.

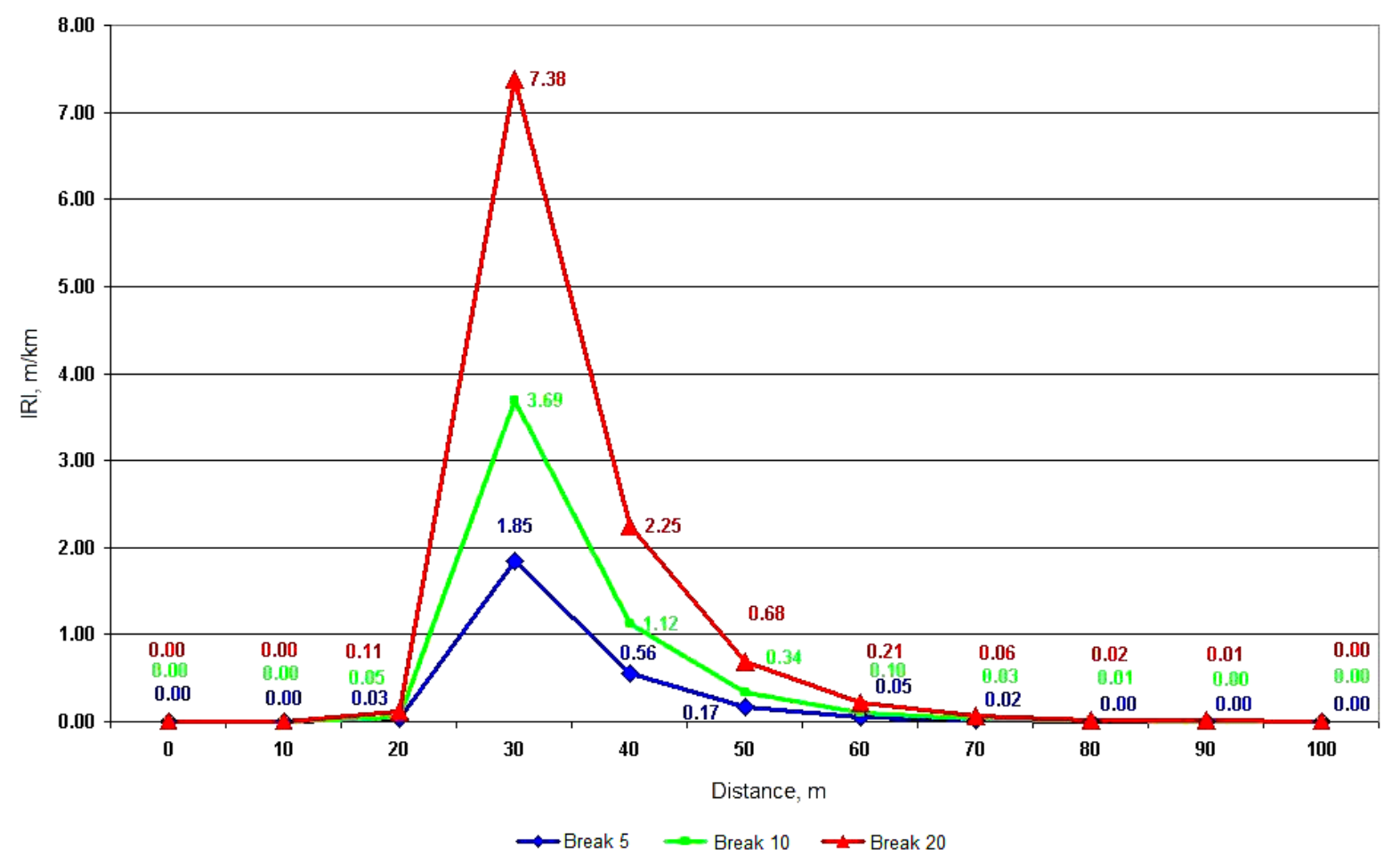

Fig. 2. A graph of the roughness index IRI after passing the road longitudinal profile break

An experiment of smoothness made for every individual element of the longitudinal profile of the road involved the analyses of straights with slopes varying from $-6 \%$ to $+6 \%$ and vertical crest and sag curves with radiuses from 2000 to 30000 meters according to methodology of international roughness index IRI [3], relying on RoadRuf software. 
Simulation of the so-called "golden car" [5] passage along the longitudinal profile elements of the road was performed during the experiment with computation of the roughness index IRI. Theoretically, the analysis revealed an entirely smooth surface of each longitudinal profile element with IRI equaling to $0 \mathrm{~m} / \mathrm{km}$. However, it is impossible to achieve that the longitudinal profile of the road is engineered taking every single element of the design line individually, since they are closely interrelated and are interdependent. Longitudinal profile of the road should be treated as an integral surface made of individual elements (straights and vertical curves).

The analysis of modelling of vehicle movement along longitudinal profile of the road consisting of two straights with algebraic difference between the slopes of which making 5,10 and 20\% in a break showed that upon passing a break the vehicle suspension acquires fluctuation (sway) of vertical movements, i.e. forced fluctuations emerge further leading to comfort reduction and increase in IRI values from 0 to $1.85,3.69$ and $7.38 \mathrm{~m} / \mathrm{km}$. Besides, the indices in question are independent of the break being crest or sag. A graph of the international roughness index variation is presented in Figure 2.

The graph reveals that a decisive influence on the roughness is made by the values of the design line in the break of the longitudinal profile of road. The major effect on IRI roughness is observed at the moment when a vehicle enters a section right after the break. The larger the break of the longitudinal profile of road, the more time is needed for a vehicle suspension vibrations/fluctuations fade away/to be suppressed and the more distance is needed for it to pass in order its original comfort is assumed. It is illustrated by the graph that a vehicle has to ride some 100 meters to reach a complete suppression of vibrations/fluctuations. This way, if a smaller distance than that of 100 meters is found between the design line breaks in the designed longitudinal profile of road, the said breaks will make an undesirable external effect on a vehicle and will cause forced vertical vibrations/fluctuations and worsen the driving comfort. Depending on the applied lengths of the longitudinal profile elements, vibrations/fluctuations may become more severe at each additional break, provided the element length is insufficient to completely suppress the emerging vibrations/fluctuations.

The design of the longitudinal profile of road shall take care of an appropriate length of its elements to be sufficient for suppressing of forced vibrations/fluctuations of the vehicle suspension.

In regard to traffic quality, viz. comfort and convenience, category I main road designed observing all standard requirements has been chosen for the longitudinal profile analysis. Height markers, i.e. road marking illustrated in Figure 3, have been put at 5 meter intervals.

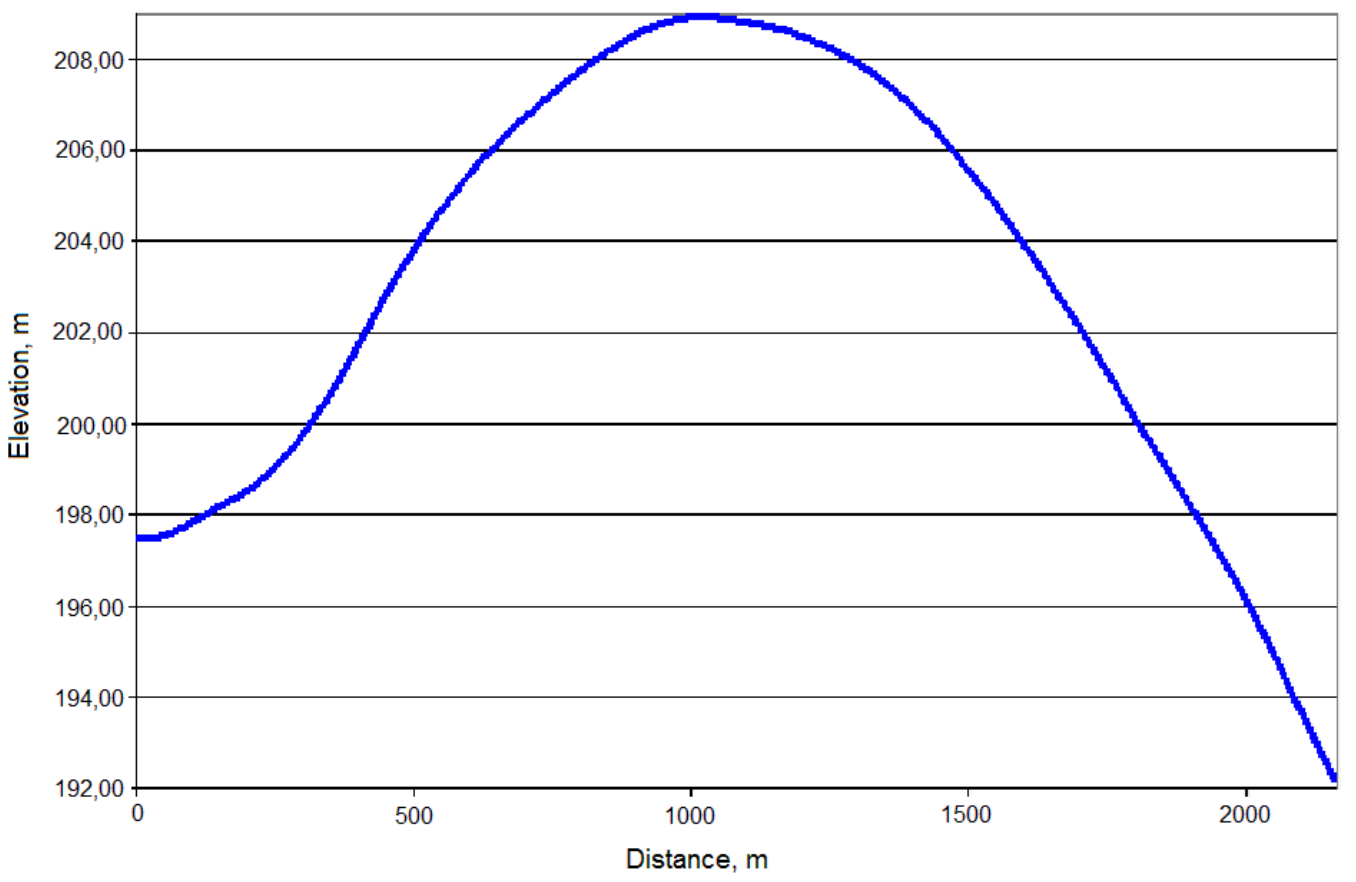

Fig. 3. Longitudinal profile of category I main road

Calculations of roughness index IRI have been performed for the longitudinal profile of the road in questions, pls. ref. to Figure 4 below.

The graph in Fig. 4 reveals the existence of the roughness index IRI peaks/outbursts even on the well-designed line of a road. The performed analysis disregards the cases of road roughness emerging as result of technological features of the road construction thus making an extra adverse impact on traffic quality. It is assumed that the construction process is going perfectly, with zero deviation from the permissible norms and with no errors (from theoretical longitudinal profile line) created by materials and equipment/machinery. 




Fig. 4. IRI variation graph of the longitudinal profile of category I main road

The analysis showed that the presence of deviations in some road sections emerging during the construction process might fail to ensure operational roughness $(1.5 \mathrm{~mm} / \mathrm{m})$ of the designed road further leading to the reduced comfort of driving a vehicle. Moreover, there are some sections of the road where the desired roughness cannot be achieved even if technological requirements are strictly followed.

The most topical issues of design of the longitudinal road profile (not necessarily, but the longitudinal road profile alone in this particular case) in the countries with well-developed motor road networks are associated with the reconstruction/upgrade of the existing road. In upgrading of the existing roads, maximum adjustment of a new design line to the existing longitudinal road profile is often undertaken (for economic purposes). Elements of the longitudinal road profile should be of sufficient length to achieve comfort of traffic however, a significant increase in reconstruction/upgrade costs may be witnessed. And again, cost reduction due to the short sections involved in the design might be achieved, but the reduction in comfort would be experienced. The issue of selection of an optimal step of a longitudinal road profile design is also critical for the reason, that quite often vertical crest and sag curves in the longitudinal road profile are interconnected without a straight insert/infix.

Reference sources of foreign countries describing the related experiments read [6], that no influence on the driving comfort and road roughness is made with the vertical curve of the longitudinal road profile making over 50 meters, as the roughness is absorbed by car suspension.

Checks of vehicle driving comfort in Belarus involved an experiment on the road with IRI $=1.4 \mathrm{~mm} / \mathrm{m}$ and 300 -metre lengths of vertical curves on the experimented road. The experiment was conducted with three different cars (not older than two years with one car equipped with driving mode selector between "auto", "comfort" and "sport"). Numerous passages with different cars and at different speed 60,90 and $160 \mathrm{~km} / \mathrm{h}$ ) were made on the same section. After each drive a driver and a passenger were interviewed about the driving comfort. Interviews indicated almost uniform comfort sensations experienced by drivers and passengers, though drivers maintained having felt slightly better than passengers. Driving at 60 $\mathrm{km} / \mathrm{h}$ speed no significant observations about driving comfort have been expressed meaning, that the car suspensions have properly absorbed fluctuations emerging due to negligible roughness and the "waves" of vertical curves have not been felt by the driver or the passenger. Driving at $90 \mathrm{~km} / \mathrm{h}$ speed was not that comfortable and pleasant for the experiment participants, only the ones driving in the car with a possible setting of the driving mode to "comfort" failed to state any discomfort due to the car suspension being "softer". Driving at $160 \mathrm{~km} / \mathrm{h}$ speed brought better feeling for the experiment participants having taken the car with the "sport" mode control. The experiment showed that the roughness emerging due to the vertical curves longer than $50 \mathrm{~m}$ have a negligible influence on the driving comfort. Driving comfort in the vertical curves of this length is more dependent on the driving speed, aerodynamic properties of the car and suspension "softness". Thus it means that two different vertical curves, i.e. crest and sag, can be interconnected in the road reconstruction/upgrade and design of longitudinal profile of road upon their checking as per IRI methodology to determine "non-comfort" sections.

For the purpose of route smoothness, road design rules in force in the USA and some Western European countries, e.g. Germany, include the requirements not only for crest and sag vertical curve radiuses, but also for the least tangent lengths (pls. ref. to Table 1) [7], [8]. 
Table 1. Radiuses of crest and sag vertical curves and their least tangent lengths [7, 8]

\begin{tabular}{|c|c|c|c|c|c|}
\hline $\begin{array}{l}\text { Road } \\
\text { category }\end{array}$ & $\begin{array}{l}\text { Design } \\
\text { class }\end{array}$ & $\begin{array}{l}\text { Speed limit } \\
(\mathrm{km} / \mathrm{h})\end{array}$ & $\begin{array}{l}\text { Minimum } \\
\text { crest radii } \\
(m)\end{array}$ & $\begin{array}{l}\text { Minimum } \\
\text { sag radii }(m)\end{array}$ & $\begin{array}{l}\text { Minimum } \\
\text { tangent } \\
\text { lengths }(m)\end{array}$ \\
\hline \multirow{4}{*}{ Motorways } & EKA 1 A & 130 & 13000 & 8800 & 150 \\
\hline & EKA 1 B & 120 & 10000 & 5700 & 120 \\
\hline & EKA 2 & 100 & 5000 & 4000 & 100 \\
\hline & EKA 3 & 80 & 3000 & 2600 & 100 \\
\hline \multirow{4}{*}{ Rural roads } & EKL 1 & 110 & $\geq 8000$ & $\geq 4000$ & 100 \\
\hline & EKL 2 & 100 & $\geq 5000$ & $\geq 3000$ & 85 \\
\hline & EKL 3 & 90 & $\geq 3000$ & $\geq 1800$ & 70 \\
\hline & EKL 4 & 70 & $\geq 2400$ & $\geq 1600$ & 55 \\
\hline
\end{tabular}

The above minimum tangent length prevents the designers from the application of very short vertical curves, which leads to the reduction of a number of breaks in the longitudinal profile of road. Besides, the regulated length of tangents enables calculation of the least distance between the design line breaks, i.e. enables determination of the design step along the longitudinal profile of road, which depends on design speed. This way, limitations for the route "waviness", which has influence on traffic quality, are defined in order to make the route smooth, harmonious and comfortable for vehicle drivers.

\section{Conclusions}

Engineering of the design line of the longitudinal profile of the road with due consideration to be given to the route smoothness and traffic quality based on the design methods applicable and experiments accomplished in the Western European countries, should take into account the following recommendations:

- Length of the elements of longitudinal profile of the engineered road should not be less than 100 meters, in order vehicle fluctuations/vibrations emerging due to the design line breaks on the road are fully suppressed/damped;

- For the route smoothness, engineering of longitudinal profile of road should avoid frequent breaks of the design line and give up breaks in the areas where a vertical curve is not designed;

- If engineering of the longitudinal profile of the reconstructed/upgraded road cannot avoid interconnection of crest and sag vertical curves with straight insert/infix missing, it should be recommended to check (on the route modelling or similar software basis) whether the lengths of these curves are in line with traffic quality in terms of the route smoothness;

- To ensure the smoothness of the route it is recommended that the design rules provide for the least design step between the design line breaks with due consideration to be given to the road category or design speed, which according to the foreign experience depends on the least applicable length of the vertical curve tangent;

- Sufficiently large radius vertical curves (both, crest and sag) are recommended to be engineered in design line breaks to form a smooth (and harmonious) spatial line of the route together with the road plan elements and to ensure the necessary visibility for stops and be adjusted to the relief and landscape of the locality.

\section{References}

[1] Sayers, M.; Gilespie, T.; Queiroz, C. 1986. The International Road Roughness Experiment: Establishing Correlation and a Calibration Standard for Measurements. Report No. UMTRI-85-15. University of Michigan Transportation Research Institute. 464 p.

[2] Sayers, M. S. 1995. On the calculation of international roughness index from longitudinal road profile. Transportation Research Record, CODEN TRREDM 1501: 9. ISSN 0361-1981: 1-12.

[3] Sayers, M. S. Two Quarter-Car Models for Defining Road Roughness: IRI and HRI, Transportation Research Record 1215: 165-172.

[4] Sayers, M. W.; Karamihas, S. M. 1998. The Little Book of Profiling: Basic Information about Measuring and Interpreting Road Profiles. University of Michigan Transportation Research Institute. $100 \mathrm{p}$.

[5] Sayers, M. W.; Gillespie, T. D.; Paterson, W. D. O. 1986. Guindelines for Conducting and Calibrating Road Roughness Measurements: World Bank Technical Paper Number 46. WTP-46/THE WORLD BANK. 98 p.

[6] Леонович, И. И.; Богданович, С. В.; Нестерович, И. В. 2011. Диагностика автомобильных дорог: учебное пособие. Минск: Новое знание; М. ИНФРА-М. $350 \mathrm{c}$.

[7] Forschungsgesellschaft für Straßen- und Verkehrswesen e.V. 2012. Richtlinien für die Anlage von Landstraßen (RAL). Köln, 137 p.

[8] Forschungsgesellschaft für Straßen- und Verkehrswesen e.V. 2008. Richtlinien für die Anlage von Autobahnen (RAA). Köln, 120 p.

[9] American Association of State Highway and Transportation Officials (AASHTO). 2011. A Policy Geometric Design Highways and Streets. Washington, $870 \mathrm{p}$.

[10] The Highways Agency. 2013. Design Manual For Roads And Bridges. UK, Volume 15. Available from Internet: gopher: www.dft.gov.uk 